\section{EDUCATION}

Research, Inovoration and Solutions on-line ${ }^{\oplus}$
Electronic Journal of Research

in Educational Psychology

PSYCHOLOGY

I+D+i

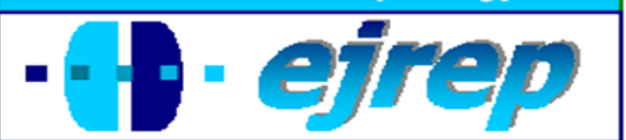

Editorial EOS

\title{
Predicting First Year University Students' Academic Success
}

\author{
Aboma Olani
}

Institute for Educational Research, University of Groningen

The Netherlands

Correspondence: Aboma Olani. Institute for Educational Research, University of Groningen, Grote Rozenstraat 3,9712TG, Groningen, The Netherlands. E-mail: A.O.Gicho@rug.nl

This article is based on a master's thesis submitted and accepted at the University of Groningen in 2008 under the supervision of Professor Greetje van der Werf.

(C) Education \& Psychology I+D+i and Editorial EOS (Spain) 


\begin{abstract}
Introduction: Premature withdrawal from university due to academic failure can present problems for students, families and educators. In an effort to widen the understanding regarding factors predicting academic success in higher institutions, prior academic achievement measures (preparatory school grade average point (GPA), aptitude test scores, and university entrance exam scores) and psychological variables (achievement motivation and academic self-efficacy) were examined to predict first year university students' GPA.

Method: Prior academic achievement records of 3301 first year university students were obtained from archival sources. From these, 214 students also filled in a self-report that gathered information concerning psychological variables. The data were analyzed using standard multiple regression analysis in order to explain the degree to which the GPA scores of first year university students were predicted from their prior academic achievements and psychological behaviors. Stepwise multiple regression analysis was employed to identify relatively the most important predictors of university GPA.
\end{abstract}

Results The result revealed that prior academic achievement measures and psychological variables in combination accounted for $17 \%$ of the variance in students' university GPA scores. The sole contribution of psychological variables was $4 \%$. Relatively a higher percentage of variance accounted for was found for females (34\%) than males (15\%). Further, preparatory school GPA was found to be the only independent significant predictor of university GPA for both sexes.

Conclusion: The results of this study support the conclusion that students' pre-college academic performances are strong predictors of GPA at university level. The effects of psychological variables on university GPA are also not negligible. Based on the findings of the study, practical implications for student support services and admissions at university and implications for research are presented.

Keywords: predicting academic success, university GPA, cognitive factor, non-cognitive variable, multiple regression

Received: 08/03/09 Initial Acceptance: 08/22/09 Final Acceptance: 10/19/09 


\section{Predicción del éxito académico de estudiantes durante el primer año de universidad}

\section{Resumen}

Introducción: El abandono universitario prematuro debido al fracaso académico puede resultar problemático para los estudiantes, las familias y los educadores. En un mayor esfuerzo para comprender los factores asociados al éxito académico en la universidad, se examinaron medidas de redimiendo académico previo (puntuación media de acceso a la universidad, PPA), puntuaciones en test de aptitud, nota de selectividad y variables psicológicas (motivación, autoeficacia) en alumnado para predecir su nota media del primer año de carrera

Método: Las puntuaciones académicas previas de 3301 estudiantes universitarios de primer año se obtuvieron mediante archives de datos previos. De la muestra total, 214 estudiantes rellenaron un autoinforme relativo a variables psicológicas. Los datos fueron analizados medainte análisis de regresión múltiple. La regresión fue utilizada para explicar el grado de predicción de la nota media obtenida durante el primer año de carrera predicha por las variables psicológicas analizadas y la puntuación media previa al ingreso en la universidad. El análisis de regresión múltiple por pasos se utilizó para identifican los predictores más importantes de la nota media del primer año de carrera.

Resultados. Los resultados muestran que la combinación de las puntuaciones académicas y las variables psicológicas explican un $17 \%$ de la varianza encontrada en las puntuaciones medias obtenidas el primer año de universidad. La contribución única de las variables psicológicas explica el 4\% de la varianza. Se observa un mayor porcentaje de la varianza explicada en nota media entre las mujeres (34\%) en comparación con los hombres $(15 \%)$. Además, la nota media de acceso a la universidad aparece como un predictor significativo para el rendimiento universitario en ambos sexos.

Conclusión. Los resultados del estudio apoyan la conclusión de el rendimiento académico previo a la universidad predice los resultados obtenidos en la universidad. Los efectos de las varaibles psicológicas en el rendimiento no son significativos. Basadas en los hallazgos del estudio, se presentan algunas implicaciones prácticas para los servicios de apoyo al estudiante y el servicio de admisión universitaria.

Palabras clave: predicción éxito académico, nota media universitaria, factor cognitivo, variables no cognitivas, regresión múltiple.

Recibido: 03/08/09 Aceptación inicial: 22/08/09 Aceptación final: 19/10/09 


\section{Introduction}

The first year in university is a critical transition period. This is because it is a time when students lay the foundation on which their subsequent academic success and persistence rest. A bulk of literature on the prediction of academic success and retention among first year university students showed that most students, despite of the academic, social, emotional, and other challenges, successfully complete the transition period and achieve academic success (e.g., DeBerad, Julka \& Spielmans, 2004). Others do not manage these challenges and are forced to leave their study at its early stage. According to Tinto (1993), the majority of students $(75 \%)$ leave college during the first two years, and 57 percent of them do so without graduation. And first year first semester university GPA is one of the major responsible factors for early drop-out from college (McGrath \& Braunstein, 1997).

Early college leaving is often associated with negative consequences for students, their families, and university administration. It can cause heavy unrealized costs to universities and families. A student leaving university without having completed her/his study may also be exposed to various psycho-social problems. Dissatisfaction with college experience, disruption of life plans, and being jobless or being engaged in minor jobs to earn much less over a life time are some among others.

The problem of attrition and its consequences can have different from in different context. Since the introduction of a new educational and training policy in 1994, expansion of higher education has been a main agenda in Ethiopia. Within the past few years, beside regional and private colleges, the number of public universities in the country has increased from 9 to 21 . Following this, the yearly public universities' acceptance rate has dramatically increased from approximately less than ten thousand (five years ago) towards nearly hundred thousand students. However, irrespective of the increment in enrollment rate, attrition rate has been frequently reported to be high in almost all public universities. The problem has been pronounced since 2004, the year in which universities have started admitting students passing through the newly introduced curriculum. Evidently, the consequences of premature departure from university become more severe in such countries where almost $44 \%$ of the population is living below the poverty line (World Bank, 2000), and where education is a main vehicle to escape from it.

The purpose of this study was to investigate the potential cognitive and non-cognitive predictors of first year university students' academic success in the Ethiopian context. If such 
factors can be well understood, it will inform policy derivatives, further research and intervention programs that can be designed to enhance success and retention rates in universities.

\section{Prediction of College GPA}

There is a relatively large body of research on the prediction of college GPA. This research focuses on two types of predictors: cognitive, ability or traditional measures, and noncognitive, affective or non-academic factors. Cognitive factors usually refer to measures such as high school grades and standardized test scores (e.g., the Standardized Aptitude Test (SAT) and the American College Testing [ACT]). And non-cognitive measures are related to psychological factors, like social support and academic related skills. Some researchers showed the importance of traditional predictors for academic success (Noble, 1991; Reason, Terenzini \& Domingo, 2006). Others emphasized on non-cognitive factors to adequately predict which students will succeed or fail in university (Tracey \& Sedlacek, 1984; White \& Sedlacek, 1986). Some others favor the combination of both to predict academic success at university (Le, Casillas, Robbins, \& Langley, 2005; Ting, 1998; Wolfe \& Johnson, 1995).

\section{Cognitive Predictors of College GPA}

The effectiveness of cognitive predictors of college performance has been well illustrated. Larson and Scontrino (1976) found that high school grade point average (GPA) and Scholastic Aptitude Test (SAT) had consistently high correlations with four-year college GPA. These correlations evidenced little shrinkage when cross-validated over either one-year or five-year periods. In the same vein, DeBerad, Julka and Spielmans (2004) demonstrated the high predictive power of SAT scores and high school GPA for academic achievement in college. They concluded that universities which are more selective in terms of high school GPA and SAT should expect greater achievement and retention among their freshman students. High school GPA and rank also appeared to have relatively high criterion-related validities with college GPA, with correlations between .44 and .62 (Kuncel, Hezlett \& Ones, 2001).

On the other hand, the predictive validity of standardized tests and high school GPA tends to be negligible especially when other variables are included in the study. McDonald and Gawkoski (1979), for example, reported that SAT and high school GPA was shown to have moderate predictive validity for first year GPA in university when other variables were included in the model. Similarly, Ting (1998) included high school GPA, SAT verbal scores, 
SAT quantitative scores, and SAT total scores along with 38 psychosocial and demographic variables in a study of students' college GPA and retention. It is only the high school GPA that was the most significant predictor of first year college GPA. However, in this study, the predictive validity of high school GPA, as well as SAT scores, was greatly influenced by other factors such as race, gender, and availability of financial aid.

\section{Non-cognitive Predictors of College GPA}

Non-cognitive variables have been defined in a different ways in the literature. Some have seen them as extracurricular or non-academic activities relating to adjustment, motivations, and perceptions (Sedlacek, 1991), while others have used the term to describe academic related skills, motivational and personality variables (Robbins, Lauver, Davis, Langley, \& Carlstrom, 2004; Le et al., 2005). Researchers have identified and studied non-cognitive variables for predicting college success. Tracey and Sedlacek (1984) offered eight variables that enhance predictions of students' success and failure at college. The variables are positive selfconcept, realistic self-appraisal, understanding of individual differences, preference for longterm over short-term goals, availability of a strong support person, successful leadership experience, demonstrated community involvement, and knowledge acquired in a field. According to the authors, these variables are useful as entrance standards for admissions of personnel, as evaluation instruments for anticipating successful GPA, persistence, and graduation, and as advising intervention tools.

Furthermore, Robbins et al. (2004) examined the relationship between various psychosocial and study skills constructs, and academic performance (GPA) and persistence by metaanalyzing 109 studies. The authors studied nine broad constructs derived from educational persistence and motivational models of college success. The nine constructs are achievement motivation, academic goals, institutional commitment, perceived social support, social involvement, academic self-efficacy, general self-concept, academic-related skills, and contextual influences. Controlling for the effects of traditional predictors (high school GPA, the ACT and the SAT scores) and socioeconomic status, they found academic self-efficacy and achievement motivation to be better predictors for college GPA.

\section{Academic Self-efficacy as a Predictor of College GPA}

Academic self-efficacy is a construct, which has its roots in Bandura's (1997) theory of self-efficacy. It is a term suggesting the possibility that self-efficacy with respect to academic 
behaviors may influence scholastic persistence and performance. Numerous studies have shown the importance of academic self-efficacy with regard to academic success. Lent, Brown and Larkin (1984) found that students reporting high academic self-efficacy generally achieved higher GPA and persisted for a longer amount of time in scientific tasks. Chemers, $\mathrm{Hu}$, and Garcia (2001) described a positive relationship between self-efficacy beliefs and both persistence and academic performance in university. Findings from the numerous studies conducted on this topic are best summarized in a meta-analysis by Multon, Brown, and Lent (1991). The result of the meta-analysis showed positive and significant relationships between self-efficacy beliefs and academic performance and persistence. Generally, research showed that students with higher levels of academic self-efficacy achieved higher university GPA and persisted in their academic major longer than those with lower perceived academic selfefficacy.

\section{Achievement Motivation as a Predictor of College GPA}

Achievement motivation is one of the basic ingredients necessary for one's success in achievement settings. Robbins et al., (2004) described it as one's motivation to achieve success, enjoyment of surmounting obstacles and completing tasks undertaken, and as a drive to strive for success and excellence. Studies have shown the predictive power of achievement motivation for academic success at college. A meta-analysis by Robbins et al. showed that achievement motivation is predictive of college students' academic performance beyond traditional predictors. Likewise, Wolfe and Johnson (1995) found that motivational variables accounted for $9 \%$ of the variance in students' first year college GPA, while SAT scores accounted for $5 \%$ of the variances. Johnston (2006) also reported a statistically significant relationship between achievement motivation and grade point average in college.

\section{Cognitive and Non-cognitive Predictors of College GPA}

Several researchers argue that the cognitive predictors such as standardized tests by themselves are inadequate for predicting which students should be admitted to colleges and universities (Anastasi, 1997; Robbins et al., 2004; Le et al., 2005; Wolfe \& Johnson 1995). Like all tests, these tests are imperfect. Hence, they are incomplete predictors of how well a student will do in college coursework. They are necessary but not sufficient markers of academic success in university. Moreover, secondary school GPA may be affected by subjectivity. Studies showed that traditional predictors, including standardized test scores and high school GPA, when used alone to predict academic performance in university, produced com- 
paratively low validity (Sedlacek, 1991; Ting \& Sedlacek, 1998). Consequently, recent studies shifted the focus to the usage of non-traditional factors together with the traditional ones to predict academic success and retention in universities. Ting and Sedlacek (1998) suggested the use of psychological variables in conjunction with traditional college success predictors for admission criteria, which according to them better explain students' academic performance. In the same vein, Le et al. (2005) indicate that there is considerable evidence supporting the use of psychological variables as complementary to the traditional criteria to predict students' academic performance and retention. Furthermore, the researchers assert that the use of psychological predictors sheds light on academic criteria and academic intervention programs for enhancing students' success at university.

In sum, literature informs us that cognitive variables alone provide limited information for predicting GPA at university. College GPA is a function of both cognitive and noncognitive variables. Findings suggest that academic and some non-cognitive factors are related to college GPA. It can therefore be councluded that more reliable prediction of college GPA tends to occur when academic and key non-academic factors are combined.

\section{The Present Study}

The use of potential predictors of college success other than the traditional ones to make prediction have been well studied and applied at some universities in the world. However, it is hard to find such information for students in Ethiopian universities where student enrolment is done in a centralized fashion on the basis of traditional predictors alone. At present, university entrance scores, aptitude test scores, and preparatory school GPA are the three indices used by the Ministry of Education to enroll students having completed preparatory programs into universities. Of particular interest to the current study thus was to find empirical support for the extent to which it was possible to predict first year, first semester university GPA on the bases of these prior academic achievement measures and psychological variables. The psychological variables included in the study were academic self-efficacy and achievement motivation. These variables were selected based on the incremental validity they have shown in predicting college GPA in a meta-analyses conducted by Robbins et al., (2004).

Two research questions guided this study: (1). What percentage of variances in students' first year first semester university GPA can be explained by their prior academic 
achievement scores (preparatory GPA, university entrance exam scores, and aptitude test scores) and by their sense of academic self-efficacy and their achievement motivation?, and (2).Which of these variables are relatively the most important in predicting students' first year first semester university GPA? Based on previous evidence it was hypothesised that students' prior academic achievement, and their levels of achievement motivation and academic selfefficacy would positively predict their first year first semester GPA implying that students with higher prior academic records, and higher levels of achievement motivation and academic self-efficacy obtain higher first year first semester university GPA.

\section{Method}

\section{Participants}

Participants were 3301 first year students enrolled to Adama University (Ethiopia) in the academic year 2007/2008. Of these 969 (29\%) were females. The mean age of the population was 18.53 ; $\mathrm{SD}=1.30$, ranging from 15 to 36 . The students were assigned at the university from all regions in the country. A sample consisting of 214 students (drawn from the total member of participants) was also formed to generate data for psychological variables. Fortythree $(20 \%)$ of them were females. The mean age of this sample was $19.50 ; \mathrm{SD}=1.31$, ranging from 17 to 27 years. The sample was formed using equal allocation method in order to include a proportional number of participants from each faculty in the university.

\section{Variables and Measures}

Prior Academic Achievement Measures. Prior achievement measures refer to preparatory GPA, university entrance scores and aptitude test scores. Preparatory GPA is individuals' total score across all subjects taught during the two year university preparatory program. The average score ranged from 0 to 800 , with 800 the highest and 0 the lowest on the scale. University entrance exam scores are subjects' total scores in the Ethiopian Higher Education Entrance Examination. The exam is given at the completion of the two years preparatory program. The score in the exam ranged from 0 (lowest) to 300 (highest). Aptitude test scores are subjects' scores on the scholastic aptitude test which is given together with the Higher Education Entrance Examination. Its score ranged from 0 (lowest) to 100 (highest). 
University GPA. First year, first semester university grade point average (GPA) was the criterion variable. The grades varied on a scale from 0 to 4 , where 0 is very poor and 4 is an excellent grade.

Academic Self-Efficacy. College Academic Self-Efficacy Scale (CASES) (Owen \& Froman, 1988) was used to measure subjects' academic self-efficacy. The scale was composed of 33 positively worded items, each measuring students' self-confidence in performing various routine academic behaviors in college. Participants had to indicate their degree of confidence on a 5-point Likert-type scale ranging from 1 (very little) to 5 (quite a lot). Sample items are: "Earning good grades in most courses", and "Listening carefully during a lecture on a difficult topic". Reliability for the CASES instrument was established by using both testretest (.90) and Cronbach's alpha (.92) methods. Adequate preliminary concurrent and factorial validity was also reported. In the present study, an estimate of internal consistency resulted in a reliability coefficient of alpha of .91 .

Achievement Motivation. Achievement motivation was measured through the Achievement Motivation Scale (AMS) (Kuyper \& Van der Werf, 2005). The scale consisted of 9 items focusing on subjects' motivation for achievement in academic settings. The items were incomplete propositions to be filled in by words/phrases assigned with numbers ranging from 1 to 4, arranged in an increasing magnitude of behavior. A sample item is: "If we have to do an examination, I study ........... I normally do", alternatives: 1-equally hard as, 2 -a bit harder than, 3-harder than, and 4- much harder than). The developers of the scale reported adequate internal consistency (.74) and evidence of predictive validity. In this study, the internal consistency using the coefficient alpha was .73.

\section{Procedure}

The academic self-efficacy and achievement motivation scales were administered to five-lecture groups, one group from each faculty, during lecture time. The scales were administered in English which is the medium of instruction in the university. A lecture group consists of an average of 50 students. Accordingly, 250 questionnaires, 50 questionnaires for each group, were distributed. Each faculty has a separate lecture building, and the selection was made by randomly picking a lecture room where the lecturers were cooperative to explain the matter to students and get the questionnaires filled in during the lecture. The five groups included were from departments namely: Electrical Engineering, International Trade and In- 
vestment Management, Information System Management, Mathematics and Psychology. This option was preferred in order to reduce missing papers by collecting completed questionnaires on the spot. The lecturers were informed to direct students when they got problems and make them complete the questionnaire within 20 minutes. Further, students' were assured of the anonymity of their response. At the end, from the 250 questionnaires that were distributed, 214 of them were usable. Then, after taking due permission from the concerned authorities, we obtained 3301 students' preparatory school GPA, aptitude test scores, university entrance exam scores as well as their first year, first semester GPA from the main registrar office of the university. Out of 3424 students enrolled to the university in that particular year, 123 students did not complete the first year, first semester program, and therefore, were not included in this study.

\section{Results}

Models for Predicting University GPA Based on Prior Academic Achievement Scores and Psychological variables

The first research question pertained to estimating a model to predict students' university GPA scores based on their prior academic achievement scores and psychological behaviors. Standard multiple regression was used for this purpose. First, prior academic achievement measures and psychological variables were analized separately to examine their independent effects on university GPA. Next, all of the predictor variables were entered in the multiple regressions analysis to test their combined effects on the criterion variable. While conducting these analyses, multicollinearity was diagnosed between university entrance exam scores and preparatory GPA (See Table 1). If two independent variables are correlated at level greater than $r=.70$, some authors (e.g., Zizzi, 2005) suggest removing one of the variables from multiple regression analysis.

However, we used the two variables together in the analysis for two reasons. The first reason was the existence of considerable difference when multiple regression analysis was conducted separately in the absence of either of the predictors. When preparatory GPA was entered in the multiple regression analysis in the absence of university entrance scores, the regression model accounted for $15 \%\left(\mathrm{R}^{2}=.15, F(5,208)=10.33, p<.0005\right)$ of the variance 
in university GPA. However, while entering university entrance scores in the analysis in the absence of preparatory GPA, the model accounted for $12 \%\left(\mathrm{R}^{2}=.12, F(5,208)=8.38, p<\right.$ $.0005)$ of the variance in the criterion variable. This shows that there is variance that is not shared by the two predictors. This could be due to the different magnitude of correlations these predictors have with the criterion variable. The other reason was lack of clear ground at hand on which to base the elimination or inclusion of one of the two variables.

Table 1. Mean, SD and Correlation matrix of Variables in the Study

\begin{tabular}{|lllllllll|}
\hline Variables & 1 & 2 & 3 & 4 & 5 & 6 & $\mathrm{M}$ & SD \\
\hline 1. PGPA & - & $.82^{* *}$ & $.45^{* *}$ & $.41^{* *}$ & & 618.31 & 62.90 \\
2. Entrance & $.83^{* *}$ & - & $.44^{* *}$ & $.35^{* *}$ & & 217.76 & 33.03 \\
3. Aptitudes & $.48^{* *}$ & $.42^{* *}$ & - & $.17^{* *}$ & & 47.63 & 8.72 \\
4. UGPA & $.41^{* *}$ & $.36^{* *}$ & $.17^{*}$ & - & & & 2.78 & .27 \\
5. Efficacy & $.45^{* *}$ & $.37^{* *}$ & $.14^{*}$ & $.17^{*}$ & - & & & \\
6. Motivation & $.24^{* *}$ & .09 & .11 & .11 & .04 & - & & \\
M & & & & & & & & \\
SD & $633.61^{*}$ & $224.80^{*}$ & $49.00^{*}$ & 2.70 & 2.52 & 3.18 & - & \\
\hline
\end{tabular}

Note: Values above the diagonal are for all participants $(\mathrm{N}=3310)$, and values below the diagonal are for the sample $(\mathrm{N}=$ 214), PGPA = preparatory GPA, UGPA = university grade average point $* p<.05$. ${ }^{*} p<.01$, 2-tailed.

The results of the multiple regression analysis showed that the use of prior achievement measures (preparatory GPA, university entrance scores and aptitude test scores) to predict first year, first semester university GPA accounted for $17 \%\left(\mathrm{R}^{2}=.17, F(3,3297)=\right.$ 225.86, $p<.0005$ ) of the total variance in students' first year, first semester GPA (See Table 2). Preparatory GPA was the only positively significant predictor of first year first semester university GPA in the model. A large amount of variance accounted for was found for females $27 \%\left(\mathrm{R}^{2}=.27, F(3,965)=116.56, p<.0005\right)$ than for males $12 \%\left(\mathrm{R}^{2}=.12, F(3\right.$, $2328)=102.89, p<.0005)$. Preparatory GPA was the only positively significant predictor of first year, first semester GPA for both sexes.

Achievement motivation and academic self-efficacy explained $4 \%\left(\mathrm{R}^{2}=.04, F(2\right.$, $212)=4.38, p<.05)$ of the variance in students' first year first semester university GPA. The proportion of variance was statistically significant. The percentage of variance in university GPA explained by the combination of the two variables was $2 \%\left(\mathrm{R}^{2}=.02, F(2,41)=.32, p\right.$ 
$=.73)$ for females and $5 \%\left(\mathrm{R}^{2}=.05, F(2,169)=3.98, p<.05\right)$ for male students. Academic self-efficacy was a positive significant predictor of first year, first semester GPA for all student groups and males but not for female students.

Prior academic achievement measures and psychological variables in combination accounted for $17 \%$ of the variance in first year first semester university GPA $\left(\mathrm{R}^{2}=.17, F(5\right.$, $208)=8.39, p<.0005)($ See Table 3$)$. For females, the prediction model accounted for $34 \%$ $\left(\mathrm{R}^{2}=.34, F(5,37)=3.82, p<.05\right)$ of the variance in university GPA. The model for females predicted considerably better than the model for males which explained $15 \%$ of the variance in university GPA $\left(\mathrm{R}^{2}=.15, F(5,165)=5.91, p<.0005\right)$. Similar to the model for all participants together, preparatory GPA was the only single significant predictor of the criterion variable in the models. The remaining predictors were found to be either positive or negative statistically non-significant predictors of first year first semester GPA.

Table 2. Summary of Multiple Regression Analyses of Predicting University GPA Using Prior Academic Achievement and Psychological Variables.

\begin{tabular}{|c|c|c|c|c|c|c|c|c|}
\hline \multicolumn{9}{|c|}{ Prior Academic Achievement Measures } \\
\hline Stud.Group & $\mathrm{n}$ & Predictors & $B$ & $\beta$ & $\mathrm{t}$ & $\mathrm{R}$ & $\mathrm{R}^{2}$ & F ratio \\
\hline \multirow[t]{4}{*}{ All } & 3301 & Constant & -.06 & & -.54 & & & \\
\hline & & PGPA & .004 & .39 & $13.82 * *$ & .41 & .17 & $225.86 * *$ \\
\hline & & Entrance & .001 & .04 & 1.47 & & & \\
\hline & & Aptitude & -.003 & -.03 & -1.63 & & & \\
\hline \multirow[t]{4}{*}{ Female } & 969 & Constant & -.16 & & -.91 & & & \\
\hline & & PGPA & .004 & .44 & $8.29 * *$ & .52 & .27 & $116.56 * *$ \\
\hline & & Entrance & .002 & .09 & 1.78 & & & \\
\hline & & Aptitude & -.001 & -.02 & -.53 & & & \\
\hline \multirow[t]{4}{*}{ Male } & 2332 & Constant & .06 & & .37 & & & \\
\hline & & PGPA & .01 & .34 & $11.19 * *$ & .34 & .12 & $102.89 * *$ \\
\hline & & Entrance & .00 & .02 & .50 & & & \\
\hline & & Aptitude & -.004 & -.04 & -1.69 & & & \\
\hline
\end{tabular}




\begin{tabular}{|c|c|c|c|c|c|c|c|c|}
\hline \multicolumn{9}{|c|}{ Psychological Variables } \\
\hline \multirow[t]{3}{*}{ All } & 214 & Constant & 1.69 & & $4.22 * *$ & & & \\
\hline & & Efficacy & .18 & .17 & $2.46^{*}$ & .20 & .04 & $4.38 *$ \\
\hline & & Motivation & .18 & .10 & 1.54 & & & \\
\hline \multirow[t]{3}{*}{ Female } & 43 & Constant & 2.07 & & $2.31 *$ & & & \\
\hline & & Efficacy & .11 & .11 & .70 & .13 & .02 & .32 \\
\hline & & Motivation & .10 & .07 & .42 & & & \\
\hline \multirow[t]{3}{*}{ Male } & 171 & Constant & 1.62 & & $3.59 *$ & & & \\
\hline & & Efficacy & .19 & .17 & $2.31 *$ & .21 & .05 & $3.98 *$ \\
\hline & & Motivation & .19 & .11 & 1.48 & & & \\
\hline
\end{tabular}

Note: $\mathrm{PGPA}=$ preparatory GPA, ${ }^{*} p<.05,{ }^{* *} p<.0005$

Models for Predicting University GPA based on Significant Predictor(s)

The second research question was concerned with identifying the most important predictors of university GPA. A stepwise multiple regression analysis revealed that preparatory GPA $(\beta=.41, p<.0005)$ was the most important single predictor of first semester university GPA (See Table 4). It explained $16 \%$ (adjusted $\mathrm{R}^{2}=.16, F(1,212)=41.5, p<.0005$ ) of the variance in students' university GPA.

The result that preparatory GPA is the sole significant predictor of university GPA was consistent across gender. It accounted for $28 \%$ (adjusted $\mathrm{R}^{2}=.28, F(1,41)=16.98, p<$ $.0005)$ and $14 \%$ (adjusted $\left.\mathrm{R}^{2}=.14, F(1,169)=29.25, p<.0005\right)$ of variance in university GPA for female $(\beta=.54, p<.0005)$ and male $(\beta=.38, p<.0005)$ students.

Table 3. Summary of Multiple Regression Analyses of Predicting University GPA Using all Predictors.

\begin{tabular}{|lllllllll|}
\hline Stud.Group & $\mathrm{n}$ & Predictors & $b$ & $\beta$ & $\mathrm{t}$ & $\mathrm{R}$ & $\mathrm{R}^{2}$ & F ratio \\
\hline All & 214 & Constant & -.20 & & -.37 & & & \\
& & PGPA & .004 & .35 & $2.71^{*}$ & & & \\
& & Entrance & .002 & .09 & .81 & .41 & .17 & $8.38^{* *}$ \\
& & Aptitudes & -.004 & -.04 & -.52 & & & \\
& & Efficacy & -.02 & -.02 & -.22 & & & \\
& Motivation & .04 & .03 & .38 & & & \\
& & & & & & & &
\end{tabular}




\begin{tabular}{|c|c|c|c|c|c|c|c|c|}
\hline \multirow[t]{6}{*}{ Female } & 43 & Constant & -.06 & & -.06 & \multirow{6}{*}{.58} & \multirow{6}{*}{.34} & \multirow{6}{*}{$3.82 *$} \\
\hline & & PGPA & .01 & .62 & $2.04 *$ & & & \\
\hline & & Entrance & .002 & .10 & .36 & & & \\
\hline & & Aptitudes & -.01 & -.08 & -.51 & & & \\
\hline & & Efficacy & -.22 & -.22 & -1.38 & & & \\
\hline & & Motivation & -.11 & -.07 & -.51 & & & \\
\hline \multirow[t]{6}{*}{ Male } & 171 & Constant & -.29 & & -.46 & \multirow{6}{*}{.39} & \multirow{6}{*}{.15} & \multirow{6}{*}{$5.91 * *$} \\
\hline & & PGPA & .004 & .29 & $2.12 *$ & & & \\
\hline & & Entrance & .002 & .10 & .83 & & & \\
\hline & & Aptitudes & -.002 & -.02 & -.19 & & & \\
\hline & & Efficacy & .014 & .01 & .16 & & & \\
\hline & & Motivation & .06 & .03 & .42 & & & \\
\hline
\end{tabular}

Note: PGPA $=$ preparatory GPA, ${ }^{*} p<.05,{ }^{* *} p<.0005$.

Table 4. Summary of Stepwise Regression Analyses of Predicting University GPA (n=214)

\begin{tabular}{|lllcccc|}
\hline Stud.Group & Model & Predictor(s) & $\mathrm{R}$ & $\mathrm{R}^{2}$ & Adjusted $^{2}$ & F-ratio \\
\hline All & 1 & PGPA & .41 & .16 & .16 & $41.50^{*}$ \\
\hline Females & 1 & PGPA & .54 & .29 & .28 & $16.98^{*}$ \\
\hline Males & 1 & PGPA & .38 & .15 & .14 & $29.25^{*}$ \\
\hline
\end{tabular}

Note: PGPA= preparatory GPA, ${ }^{*} p<.0005$.

\section{Discussion}

The purpose of the study was to develop a model for predicting first year first semester GPA, and to identify the most important predictor of university GPA. The result showed that pre-college performance explained the largest proportion of the variance in university GPA with preparatory GPA as the only significant predictor in the model. This means that students who performed better during the pre-college period also performed better in university. Probably these students had the potential to easily cope with the academic atmosphere in universities more easily than others. This may also imply the relevance of the content being taught in preparatory schools in preparing students for university. The result that preparatory GPA is a 
single best predictor of university GPA more than standardized test scores, is in agreement with previous findings (Ting, 1998; Anastasi, 1997; Wolfe \& Johnson, 1995).

The possible explanation why the other prior academic achievement measures (university entrance scores and aptitude test scores) failed to be significant predictors of university GPA could be that these exams are one shot exams. They are administered every year at one specific moment. Obviously, such exams are susceptible to factors that can distort examinees' true score. Among others, test anxiety and cheating during examination can be mentioned. Moreover, these exams may lack proper test quality which can hinder their predictive power. As far as the knowledge of the researcher is concerned, these exams have never been studied for reliability and validity.

The association observed between psychological predictors (academic self-efficacy and achievement motivation) and university GPA was generally weaker than the one observed between prior academic measures and university GPA. However, contrary to the finding in the current study, these variables were earlier found to be the best predictors of university GPA with contributions of $23.5 \%$ and $25.2 \%$ of the variance in university GPA respectively (Robinson et al., 2004). One possible reason for the small predictive power of these psychological variables in this study could be that the Ethiopian culture, just like most collective cultures, encourages modesty and lacks self-enhancement motive. Thus, students' rating may not represent their actual motivation and sense of self efficacy in an academic setting. Another possible reason may be that respondents would have reported false behaviors or carelessly filled in the inventories. Social desirability bias could also be an additional reason that can be mentioned.

A gender difference was observed in the current study. Predictor variables explained more of the variance in university GPA for female than for male students. This implies that the model was stronger for predicting first year first semester GPA for females than for males. This finding coincides with a study conducted by Ting (2001).

In conclusion, the findings of this study support the hypothesis that prior academic achievements, particularly academic performances during high school or college preparation programs are important determinants of university GPA. There is also evidence that psychological behaviors affect academic performances of students with similar prior academic back- 
ground. Nevertheless, this study is not free from limitations. Especially the following limitations should be taken it to account before any form of generalization can be made of the result of this study. First, as the study was confined to one university, the results may not necessarily apply to students in other universities in the country. Second, this study focused on some potential student variables affecting performance at university (prior academic achievements and psychological variables). Institutional and environmental variables that play great role in the prediction of college success (e.g., Tinto, 1993) were not considered. The third limitation was inability to include more than one semester's university GPA. Finally, lack of related studies in similar research settings limited the possible comparisons that could be made.

In spite of these limitations, this study has important practical implications and implications for research. The findings of this study suggest the necessity of special educational support programs for students with low prior academic records. In this regard, teachers/administrators can use prior academic achievement measures, especially preparatory GPA to identify students who need to be supported. Possible assistances such as tutorial classes, guidance on study skills, note taking and other basic academic skills can be organized. Secondly, post-preparatory selection and placement decisions based on prior academic measures should allot different weights for the indices involved. According to the findings of this study, more weight should be given to preparatory/high school GPA than to the national aptitude and university entrance scores. Third, any predictions of college success need to take group differences into consideration, especially females and males should not be predicted using one general model; because it would likely leads to prediction bias. Fourth, the findings of this study calls for indepth study on the reliability and validity of the national aptitude and university entrance examinations. Finally, it would also be useful to devote further study in other universities in Ethiopia by considering institutional and environmental variables as well as by extending the measures for success at university to variables such as retention, graduation or more psychological outcomes like satisfaction and well-being. 


\section{References}

Anastasi, A. (1997). Psychological Testing. ( $7^{\text {th }}$ edn). New York: Prentice Hall International.

Bandura, A. (1997). Self-Efficacy: The exercise of control. New York: W.H. Freeman and Company.

Chemers, M. M., Hu, L. T., \& Garcia, B. F. (2001). Academic self-efficacy and first-year college student performance and adjustment. Journal of Educational Psychology, 93(1), 55-64.

DeBerard, S. M., Julka, D. L. \& Spielmans, G. I. (2004). Predictors of academic achievement and retention among college freshmen: A longitudinal study. College Student Journal, $38,66-85$.

Johnston, C. G. (2006). Predictors of college success among African-American, Caucasian, and Hispanic students. Dissertation. Texas Tech University. Retrived on Decemver, 12, 2008 from: http://hdl.handle.net/2346/1100

Kuncel, N. R., Hezlett, S. A., \& Ones, D. S. (2001). A comprehensive meta-analysis of the predictive validity of the Graduate Record Examinations: Implications for graduate student selection and performance. Psychological Bulletin, 127, 162-181.

Kuyper, H. \& Van der Werf, M. P. C. (2005). VOCL' 99 - 3: Prestaties en opvattingen vanleerlingen in de derde klus van het voortgezet ouderwijs (VOLC' 99-3 achievements and beliefs of students in the third grade of secondery education). Groningen: GION.

Larson, J. R., \& Scontrino, P. (1976). The consistency of high school grade point average and the verbal and mathematical portions of the Scholastic Aptitude Test of the College Entrance Examination Board, as predictors of college performance: An eight year study. Educational and Psychological Measurement, 36, 439-43.

Le, H., Casillas, A., Robbins, S. B., \& Langley, R. (2005). Motivational and skills, social, and self- management predictors of college outcomes: Constructing the Student Readiness Inventory. Educational and Psychological Measurement, 62, 1-28.

Lent, R. W., Brown, S. D., \& Larkin, K. C. (1984). Relation of self-efficacy expectations to academic achievement and persistence. Journal of Counselling Psychology, 31, 356-362.

McDonald, R. T., \& Gawkoski, R.S. (1979). Predictive value of SAT scores and high school achievement for success in a college honours programme. Educational and Psychological Measurement, 39,411-414. 
McGrath, M. \& Braunstein, A. (1997). The prediction of freshmen attrition: An examination of the importance of certain demographic, academic, financial, and social factors. College Student Journal, 31, 396-408.

Multon, K. D., Brown, S. D. \& Lent, R. W. (1991). Relation of self-efficacy beliefs to academic outcomes: A meta-analytic investigation. Journal of Counselling Psychology, $38,30-38$.

Noble, J. P. (1991). Predicting college grades from ACT assessment scores and high school course work and grade information (Rep. No. ACT-RR-91-3). Iowa City, IA: American College Testing Program. (ERIC Document Reproduction Service No. ED344943).

Owen, S.V. \& Froman, R.D. (1988). Development of an Academic Self-Efficacy Scale. A paper presented at the Annual Meeting of the National Council on Measurement in Education, New Orleans.

Reason, R.D., Terenzini, P.T., Domingo, R.J. (2006). Developing academic competence in the first year of college. Research in Higher Education, 47 (2), 149-158.

Robbins, S. B., Lauver, K., Le, H., Davis, D., Langley, R., \& Carlstrom, A. (2004). Do psychosocial and study skills factors predict college outcomes? A meta-analysis. Psychological Bulletin, 130, 261-288.

Sedlacek, W. E. (1991). Using noncognitive variables in advising nontraditional students. The Journal of the National Academic Advising Association, 11, 75-82.

Ting, S. R. (1998). Predicting first-year grades and academic progress of college students of first-generation and low-income families. Journal of College Admission, 158, 1423.

Ting, S.R. (2001). Predicting academic success of first year engineering students from standardized test sore and psychological variables. International Journal of Engineeing Edducation, 17, 75-80.

Ting, S.R. \& Sedlacek, W.E. (1998).Validity of the noncognitive questionnaire-revised 2 in predicting the academic success of university freshmen: Research Report Retrieved on December, 26, 2007 from http://williamsedlacek.info/publications/articles/validity100.html - 99k

Tinto, V. (1993). Leaving college; Rethinking the causes and cures of student attrition ( $2^{\text {nd }}$ ed.). Chicago: University of Chicago Press.

Tracey, T. J., \& Sedlacek, W. E. (1984). Noncognitive variables in predicting academic 
success by race. Measurement and Evaluation in Guidance, 16, 171-178.

White, T. J., \& Sedlacek, W. E. (1986). Noncognitive predictors of grades and retention for specially admitted students. Journal of College Admissions, 3, 20.

Wolfe, R. N. \& Johnson, S. D. (1995). Personality as a predictor of college performance. Educational and Psychological Measurement, 55, 177-85.

World Bank (2000).World development Indicators. Development Data Center, Washington.

Zizzi, S. (2005). SS 726 - multiple regressions. Virginia University. 